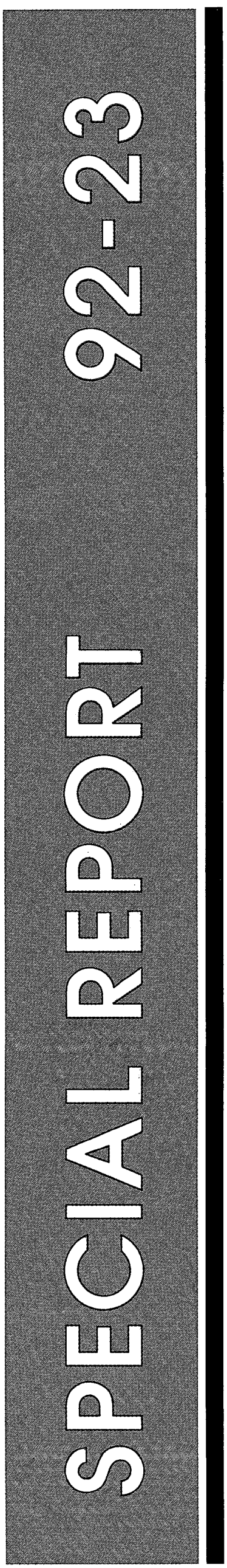

\title{
Potential Cause for Low Lead and Chromium Recoveries During Acid Extractions
}

Alan D. Hewitt and James H. Cragin 


\begin{abstract}
When high concentrations ( $\geq 100 \mathrm{mg} / \mathrm{L}$ ) of $\mathrm{Pb}$ and $\mathrm{Cr}$ (IV) are present together in solution, $\mathrm{PbCrO}_{4}$ precipitates, resulting in losses of these two metals. Moderate acidification with $1-2 \% \mathrm{HNO}_{3}$ does not prevent precipitation loss. Caution is necessary when preparing standard solutions or handling acidic extracts of environmental samples containing high levels of $\mathrm{Pb}$ and $\mathrm{Cr}$, since undetected formation of metal chromates will result in low recoveries of these metals.
\end{abstract}

For conversion of SI metric units to U.S./British customary units of measurement consult ASTM Standard E380, Metric Practice Guide, published by the American Society for Testing and Materials, 1916 Race St., Philadelphia, Pa. 19103.

This report is printed on paper that contains a minimum of $50 \%$ recycled material. 


\section{Special Report 92-23}

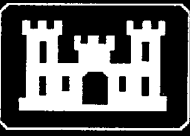

U.S. Army Corps of Engineers

Cold Regions Research \&

Engineering Laboratory

\section{Potential Cause for Low Lead and Chromium Recoveries During Acid Extractions}

Alan D. Hewitt and James H. Cragin 


\section{PREFACE}

This report was prepared by Alan D. Hewitt, Research Physical Scientist, Geological Sciences Branch, and James H. Cragin, Research Chemist, Snow and Ice Branch, Research Division, U.S. Army Cold Regions Research and Engineering Laboratory.

Funding was provided through the U.S. Army Toxic and Hazardous Materials Agency (USATHAMA), Durant Graves, Project Monitor, and by DA Project 4A161102AT24, Work Unit 003, Properties of Cold Regions Boundary Layer Constituents.

The authors thank Dr. Clarence Grant (University of New Hampshire) and Daniel Leggett (CRREL) for critical review of the manuscript.

This publication reflects the views of the authors and does not suggest or reflect policy, practices, programs or doctrine of the U.S. Army or of the Government of the United States. The contents of this report are not to be used for advertising or promotional purposes. Citation of brand names does not constitute an official endorsement or approval of the use of such commercial products. 


\title{
Potential Cause for Low Lead and Chromium Recoveries During Acid Extractions
}

\author{
ALAN D. HEWITT AND JAMES H. CRAGIN
}

\section{INTRODUCTION}

The most common techniques in use today for the determination of trace levels of pollutant metals in environmental samples are atomic absorption and atomic emission. Analytical interferences can be either instrumental or chemical. Many of the chemical interferences have been overcome by varying instrumental parameters, adding matrix modifiers or using optimal sample atomization techniques. However, chemical interferences causing elemental losses can also occur before analysis-e.g., incomplete sample dissolution or volatilization of compounds during sample treatment. Other than potential loss of $\mathrm{Pb}$ halides or the formation of sparingly soluble $\mathrm{PbSO}_{4}$, we found no mention in the literature of solution losses or even the compatibility of $\mathrm{Pb}$ and $\mathrm{Cr}$ when mixed metal standards from certified reference stock solutions are prepared.

Commercially, Cris available in $1000 \mathrm{ppm}(\mathrm{mg} /$ L) certified reference stock solutions as $\mathrm{K}_{2} \mathrm{Cr}_{2} \mathrm{O}_{7}$ or $\left[\mathrm{NH}_{4}\right]_{2} \mathrm{Cr}_{2} \mathrm{O}_{7}$ in water. When introduced as the dichromate salt, the following species are present if the solution is aqueous or acidified with either $\mathrm{HClO}_{4}$ or $\mathrm{HNO}_{3}: \mathrm{CrO}_{4}{ }^{2-}, \mathrm{HCrO}_{4}^{--}, \mathrm{Cr}_{2} \mathrm{O}_{7}{ }^{2-}$ and $\mathrm{H}_{2} \mathrm{CrO}_{4}$ (Cotton and Wilkinson 1988). If $\mathrm{HCl}$ is used for acidification, then the chlorochromate anion $\left(\mathrm{CrO}_{3} \mathrm{Cl}^{-}\right)$is the dominant species (Cotton and Wilkinson 1988). Thus, unlike many metals, chromium (VI) exists as anionic species in solution and, if present as chromate ion $\left(\mathrm{CrO}_{4}{ }^{2}\right)$, can cause losses of some heavy metal cations (i.e., $\mathrm{Ba}^{2+}, \mathrm{Pb}^{2+}$ and $\mathrm{Ag}^{+}$) by precipitation of insoluble chromates (Cotton and Wilkinson 1988). The absence of cau- tion regarding such losses in common solution chemistry references (Katz and Jenniss 1983, Slavin 1984, Sulcek and Povondra 1989) is especially surprising for $\mathrm{Pb}$, since the classical method for qualitative identification of the presence of this element is by precipitation of $\mathrm{PbCrO}_{4}$ (Lyde 1961).

Recently, while doing quality assurance testing of a metal extraction procedure for soils using $\mathrm{HNO}_{3}$ and a microwave oven, it was necessary to mixanalytical referencestandards containing 1000$\mathrm{mg} / \mathrm{L}$ concentrations of both $\mathrm{Cr}$ and $\mathrm{Pb}$. Here, we describe problems encountered when mixing commercially available standards of these two metals; an analogous problem also may exist in the preparation of hazardous waste samples.

\section{EXPERIMENTAL}

The extraction procedure being evaluated in our study uses a 0.5 -g soil subsample and $10 \mathrm{~mL}$ of concentrated $\mathrm{HNO}_{3}$ sealed in a $120-\mathrm{mL}$ Teflon vessel (Hewitt and Reynolds 1990). Dissolution is effected by heating in a microwave oven to temperatures approaching $120^{\circ} \mathrm{C}$ for approximately 13 minutes. Mixed metal standards for spiking were prepared from $1000-\mathrm{mg} / \mathrm{L}$ certified reference standards purchased from Fisher Scientific. As received, all of the reference standards other than $\mathrm{Cr}$ were acidified to 2 or $5 \%$ with $\mathrm{HNO}_{3}$. The chromium standard was prepared by dissolution of potassium dichromate in water. Aliquots of As, $\mathrm{Cd}, \mathrm{Cr}, \mathrm{Cu}, \mathrm{Pb}$ and $\mathrm{Zn}$ were combined and taken to $100 \mathrm{~mL}$ with Type 1 water (Milli Q) to produce a concentrated standard spiking solution of $\mathrm{pH} 0.4$ 
Table 1. Metal concentration $(\mu \mathrm{g} / \mathrm{L})$ determined in the diluted (1:400) mixed metal spiking solution.

\begin{tabular}{lccccc} 
& As & $C d$ & $C u$ & $C r$ & $P b$ \\
\hline Expected & 80.0 & 4.00 & 400 & 400 & 500 \\
Measured & 84.5 & 3.81 & 412 & 319 & 46.1 \\
Percent recovered & 106 & 95.2 & 103 & 79.8 & 9.22 \\
\hline
\end{tabular}

containing $200 \mathrm{mg}$ of $\mathrm{Pb} / \mathrm{L}$ and $160 \mathrm{mg}$ of $\mathrm{Cr} / \mathrm{L}$, from which a series of dilutions was subsequently made, as described in detail elsewhere (USATHAMA 1990). Concentrations of As, Cd, $\mathrm{Cr}, \mathrm{Cu}$ and $\mathrm{Pb}$ in soil extracts and spiked quality assurance samples were determined by Graphite Furnace Atomic Absorption Spectrometry (GFAAS) using a Perkin-Elmer Model 5100PC Zeeman atomic absorption spectrometer.

\section{RESULTS AND DISCUSSION}

Prior to the quality control spike and recovery test, we analyzed the stock spiking solution to verify that the metal concentrations were as expected (Table 1). On the basis of the procedure to be used for the spike recovery test, a $0.25-\mathrm{mL}$ aliquot was removed from the mixed metal stock solution and diluted to $100 \mathrm{~mL}$ in a $10 \% \mathrm{HNO}_{3}$ solution (1:400 dilution). The concentrations of As, $\mathrm{Cd}$ and $\mathrm{Cu}$ were within $\pm 6 \%$ of their expected values, but the recoveries both $\mathrm{Pb}$ and $\mathrm{Cr}$ were low at 9.2 and $80 \%$, respectively, of the expected concentrations. Since $\mathrm{Pb}$ and $\mathrm{Cr}$ were lost in equimolar quantities, the low values were attributed to precipitation of $\mathrm{PbCrO}_{4}$.

We conducted two experiments to determine the upper concentration limits of $\mathrm{Pb}$ and $\mathrm{Cr}$ in typical mixed metal reference stock solutions, and to assess the effect of acidity on their loss from solution. In the first experiment $\mathrm{Pb}$ and $\mathrm{Cr}$ were mixed in $2 \% \mathrm{HNO}_{3}$ in the following concentrations (mg/L) -2.0/1.6, 10/8, 20/16 and 100/80. These solutions sat overnight prior to dilution (1:400) and determination of $\mathrm{Pb}$ (Table 2). At concentrations of $20 \mathrm{mg} / \mathrm{L}$ and below, quantitative recoveries of $\mathrm{Pb}$ were obtained. At the $100 \mathrm{mg} / \mathrm{L}$ level, however, only $23 \%$ of the $\mathrm{Pb}$ was recovered.

In the second experiment the $\mathrm{Pb}$ and $\mathrm{Cr}$ concentrations were held constant and the acidity was varied. Thoroughly mixed solutions containing $200 \mathrm{mg} / \mathrm{L}$ of $\mathrm{Pb}$ and $\mathrm{Cr}$ were prepared in 1.0, 2.6, $5.0,7.6$ and $10 \% \mathrm{HNO}_{3}$. Aliquots were withdrawn without further solution agitation after 1,2,3,4,6, 8,10 and 14 days, diluted (1:400) and analyzed by GFAAS.

Figure 1 shows the percentage of the original $200 \mathrm{mg}$ of $\mathrm{Pb} / \mathrm{L}$ remaining in solution over a 2week period. Overall, the higher the acid concentration, the higher the initial (1-day) and final (14day) $\mathrm{Pb}$ concentrations. Lead precipitated as the chromate almost immediately from both the 1.0 and $2.6 \%$ acid solutions, while $\mathrm{PbCrO}_{4}$ formation took hours and days for the 5.0 and $7.5 \%$ acid solutions respectively. No precipitate was observed in the $10 \%$ acid solution and $\mathrm{Pb}$ levels remained at the original $200 \mathrm{mg} / \mathrm{L}$ for the duration of the experiment (14 days), probably because of increased solubility of $\mathrm{PbCrO}_{4}$ at this acidity. Unlike the $10 \%$ acid solution, the $\mathrm{Pb}$ concentration in all of the other acid solutions was not constant with

Table 2. Recoveries of mixed metal stock standards $(\mathrm{mg} / \mathrm{L})$ acidified with $2 \% \mathrm{HNO}_{3}$.

\begin{tabular}{lrccc}
\hline $\mathrm{Pb} / \mathrm{Cr}$ concentration & $2.0 / 1$ & $10 / 8$ & $20 / 16$ & $100 / 80$ \\
Measured $\mathrm{Pb}$ & 2 & 10.5 & 20.4 & 23.0 \\
Percent recovered & 100 & 105 & 102 & 23 \\
\hline
\end{tabular}




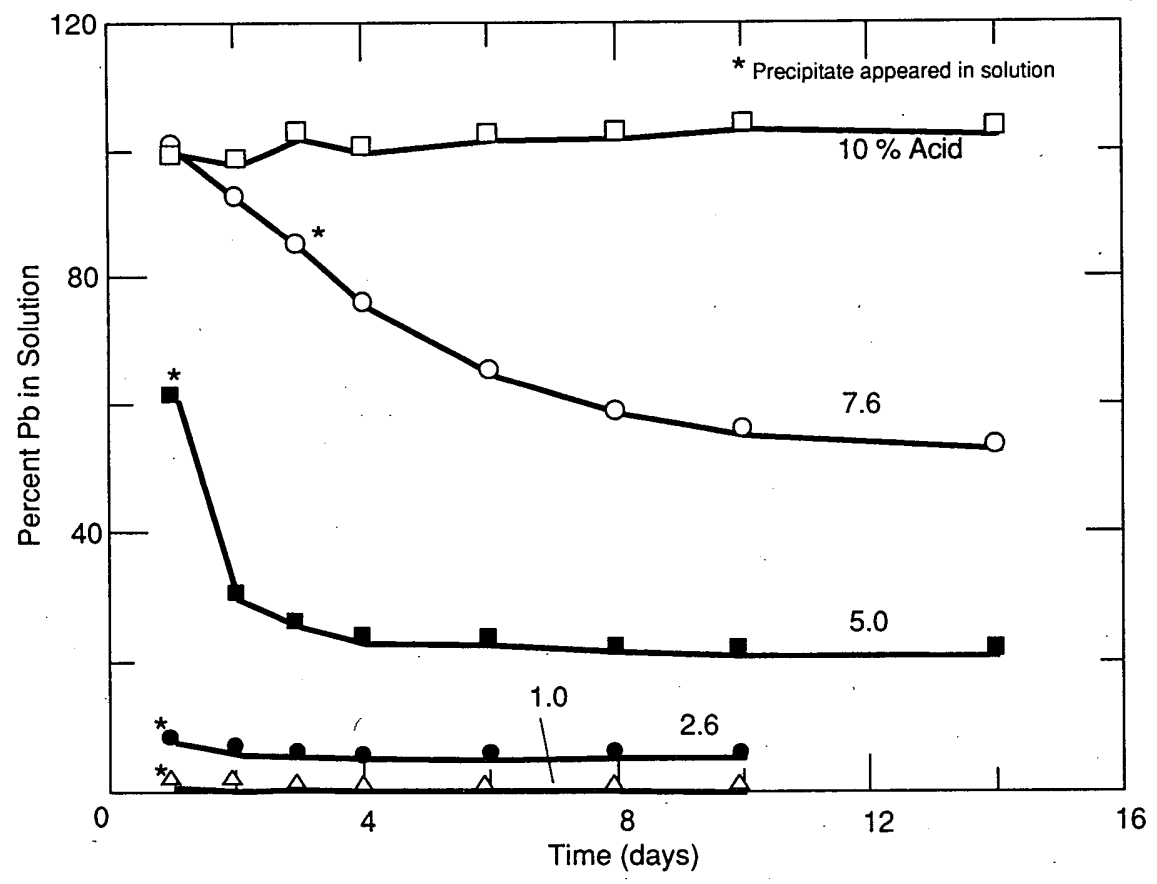

Figure 1. Percent of $\mathrm{Pb}$ (original concentration $200 \mathrm{mg} / \mathrm{L}$ ) versus time in solutions of various acidity.

time. In $7.6 \%$ acid, the $\mathrm{Pb}$ concentration was still $200 \mathrm{mg} / \mathrm{L}$ after 1 day, then gradually decreased to about $54 \%$ ( $108 \mathrm{mg} / \mathrm{L})$ of this value after 14 days. In $5.0 \%$ acid, the $\mathrm{Pb}$ concentration was $120 \mathrm{mg} / \mathrm{L}$ after 1 day, decreased to about $48 \mathrm{mg} / \mathrm{L}$ after $4-6$ days, and thereafter remained stable. The $2.6 \%$ acid solution had a $\mathrm{Pb}$ concentration of $16 \mathrm{mg} / \mathrm{L}$ after 1 day, then decreased slightly and stabilized at $12 \mathrm{mg} / \mathrm{L}$ after 3 days. The $1 \%$ acid solution had a $2.9-\mathrm{mg} / \mathrm{L} \mathrm{Pb}$ concentration on day 1 , then decreased and stabilized at $2.0 \mathrm{mg} / \mathrm{L}$ thereafter.

The above observations show that the final concentrations of $\mathrm{Pb}$ and $\mathrm{Cr}$ in concentrated solutions are controlled by not only acidity and solubility but by kinetics as well. For solutions containing $200 \mathrm{mg} / \mathrm{L}$ of $\mathrm{Pb}$ and $\mathrm{Cr}$, acidification with $\mathrm{HNO}_{3}$ in the range of $2-8 \%$ leads to kinetically slow (on the order of days) precipitation of these metals. The slow rate of precipitation is possibly caused by the low $\mathrm{CrO}_{4}{ }^{2-}$ concentrations present in acidic solution, or the slow dissociation rate of $\mathrm{H}_{2} \mathrm{CrO}_{4}$ or $\mathrm{HCrO}_{4}^{-}$, or both, to the chromate ion.

Acidity affects the chromium $\left(\mathrm{CrO}_{4}{ }^{2-}\right)$ concentration, which in turn controls the $\mathrm{Pb}$ concentration. The equilibria and ionization constants (Lange and Forker 1966) involved can be shown as follows (for simplicity we assume activities are unity)

$$
\begin{aligned}
& \mathrm{H}_{2} \mathrm{CrO}_{4} \rightleftharpoons \mathrm{H}^{+}+\mathrm{HCrO}_{4}^{-} \\
& \mathrm{K}_{1}=\frac{\left[\mathrm{H}^{+}\right]\left[\mathrm{HCrO}_{4}^{-}\right]}{\left[\mathrm{H}_{2} \mathrm{CrO}_{4}\right]}=1.8 \times 10^{-1} \\
& \mathrm{HCrO}_{4}^{-} \rightleftharpoons \mathrm{H}^{+}+\mathrm{CrO}_{4}^{2-} \\
& \mathrm{K}_{2}=\frac{\left[\mathrm{H}^{+}\right]\left[\mathrm{CrO}_{4}^{2-}\right]}{\left[\mathrm{HCrO}_{4}^{-}\right]}=3.2 \times 10^{-7} \\
& \mathrm{~Pb}^{2+}+\mathrm{CrO}_{4}^{2-} \rightleftharpoons \mathrm{PbCrO}_{4} \\
& \mathrm{~K}_{\mathrm{sp}}=\left[\mathrm{Pb}^{2+}\right]\left[\mathrm{CrO}_{4}^{2-}\right]=1.77 \times 10^{-14}
\end{aligned}
$$

The first two equations can be combined to give expressions for the fraction $(\alpha)$ of each chromium species that is present in solution at any given $\mathrm{pH}$.

$$
\alpha_{\mathrm{H}_{2} \mathrm{CrO}_{4}}=\frac{\left[\mathrm{H}^{+}\right]^{2}}{\left[\mathrm{H}^{+}\right]^{2}+\mathrm{K}_{1}\left[\mathrm{H}^{+}\right]+\mathrm{K}_{1} \mathrm{~K}_{2}}
$$




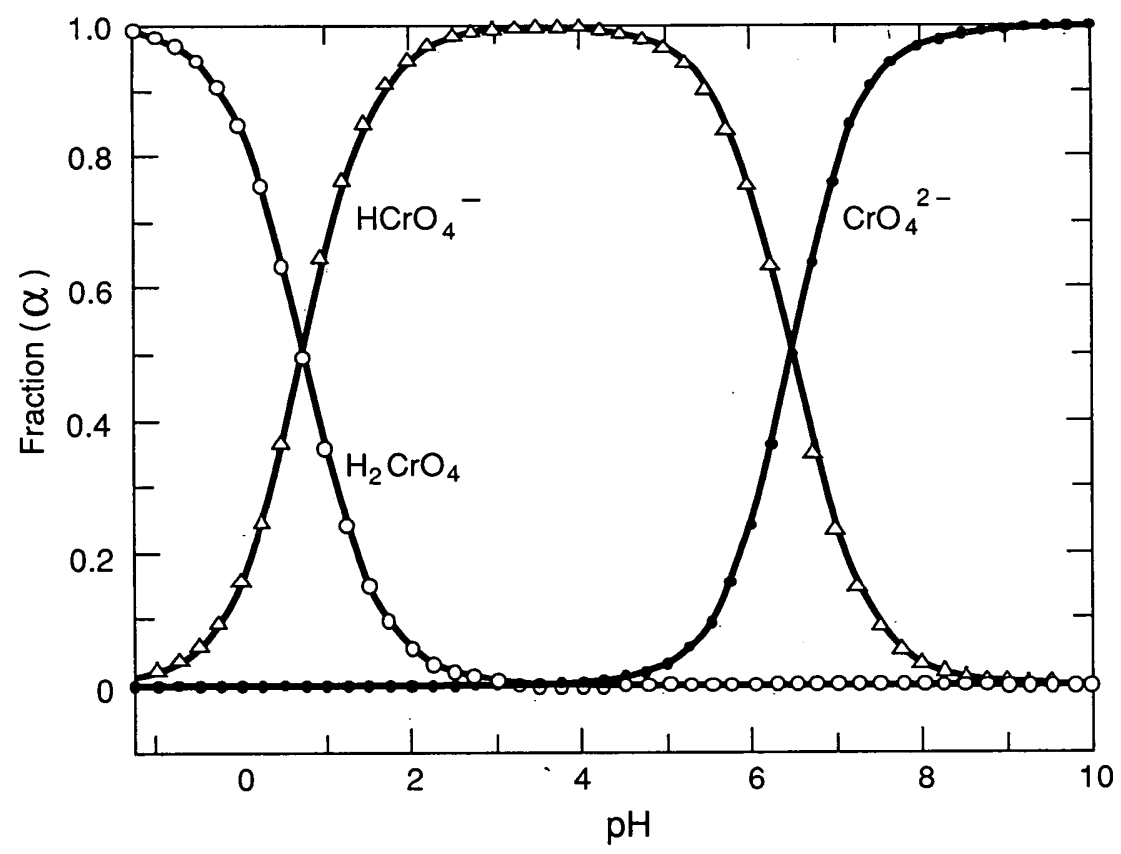

- Figure 2. Fraction of chromium species versus $p H$.

$$
\begin{aligned}
& \alpha_{\mathrm{HCrO}_{4}}=\frac{\mathrm{K}_{1}\left[\mathrm{H}^{+}\right]}{\left[\mathrm{H}^{+}\right]^{2}+\mathrm{K}_{1}\left[\mathrm{H}^{+}\right]+\mathrm{K}_{1} \mathrm{~K}_{2}} \\
& \alpha_{\mathrm{CrO}_{4}{ }^{2-}}=\frac{\mathrm{K}_{1} \mathrm{~K}_{2}}{\left[\mathrm{H}^{+}\right]^{2}+\mathrm{K}_{1}\left[\mathrm{H}^{+}\right]+\mathrm{K}_{1} \mathrm{~K}_{2}} .
\end{aligned}
$$

Since the acid dissociation constants do not change, the only controlling variable is $\mathrm{pH}$. From the $\mathrm{pH}$ and eq 4-6, we calculated the fraction of each chromium species present. A plot (Fig. 2) of this fraction vs $\mathrm{pH}$ shows that below $\mathrm{pH} 0.7$ the predominant species is $\mathrm{H}_{2} \mathrm{CrO}_{4}$, between $\mathrm{pH} 0.7$ and $6.5 \mathrm{HCrO}_{4}{ }^{-}$predominates, and above $\mathrm{pH} 6.5$ $\mathrm{CrO}_{4}{ }^{2-}$ is the major species. The $\mathrm{pHs}$ of acidified

Table 3. Acid concentrations and pHs of solutions used to study the effect of acidity upon $\mathrm{Pb}$ losses.

\begin{tabular}{ccc}
$\begin{array}{c}\text { Acid concentration } \\
(\%)\end{array}$ & $p H$ & $\begin{array}{c}{\left[\mathrm{H}^{+}\right]} \\
(\mathrm{mg} / \mathrm{L})\end{array}$ \\
\hline 1.0 & 0.80 & 0.16 \\
2.6 & 0.39 & 0.41 \\
5.0 & 0.097 & 0.79 \\
7.6 & -0.079 & 1.2 \\
10.0 & -0.20 & 1.6 \\
\hline
\end{tabular}

solutions used in this study (Table 3 ) were all less than 0.8 , so that the predominant chromium species in solution was $\mathrm{H}_{2} \mathrm{CrO}_{4}$.

The equilibrium concentration of each chromium species can be found by multiplying the total initial chromium concentration by the fraction of that particular species present at a given acidity. For example, the concentration of chromate ion is

$$
\left[\mathrm{CrO}_{4}{ }^{2-}\right]=[\mathrm{Cr} \text { Total }] \alpha_{\mathrm{CrO}_{4}{ }^{2-}} .
$$

Since $\alpha_{\mathrm{CrO}_{4}{ }^{2-}}$ is given by eq 6 and $\mathrm{Cr}$ Total is 200 $\mathrm{mg} / \mathrm{L}$, solving for the chromate ion concentration in $1 \%(0.16 \mathrm{~m} / \mathrm{L})$ acid, we have

$$
\begin{aligned}
& {\left[\mathrm{CrO}_{4}^{2-}\right]=(200 \mathrm{mg} / \mathrm{L})} \\
& \frac{(0.18)\left(3.2 \times 10^{-7}\right)}{(0.16)^{2}+(0.18)(0.16)+(0.18)\left(3.2 \times 10^{-7}\right)}
\end{aligned}
$$

$$
\begin{aligned}
& {\left[\mathrm{CrO}_{4}{ }^{2-}\right]=} \\
& \quad 2.1 \times 10^{-4} \mathrm{mg} / \mathrm{L} \text { or } 2.1 \times 10^{-7} \mathrm{~g} / \mathrm{L} .
\end{aligned}
$$

Knowing the $\mathrm{CrO}_{4}^{2-}$ concentration, we can calculate the $\mathrm{Pb}^{2+}$ concentration from the solubility product 


$$
\begin{aligned}
{\left[\mathrm{Pb}^{2+}\right] } & =\frac{1.77 \times 10^{-14} \mathrm{~mol}^{2} / \mathrm{L}^{2}}{1.8 \times 10^{-9} \mathrm{~mol} / \mathrm{L}} \\
& =9.8 \times 10^{-6} \mathrm{~mol} / \mathrm{L} \\
{\left[\mathrm{Pb}^{2+}\right] } & =2.0 \mathrm{mg} / \mathrm{L}
\end{aligned}
$$$$
\left[\mathrm{Pb}^{2+}\right]\left[\mathrm{CrO}_{4}{ }^{2-}\right]=1.77 \times 10^{-14} \mathrm{~mol}^{2} / \mathrm{L}^{2}
$$

Thus, in the $1 \%$ (pH0.8) acid solution, the theoretical equilibrium $\mathrm{Pb}$ concentration is $2.0 \mathrm{mg} / \mathrm{L}$, in excellent agreement with the observed concentration $(2.0 \mathrm{mg} / \mathrm{L})$. Theoretical equilibrium $\mathrm{Pb}$ concentrations for other acidities were calculated simi-

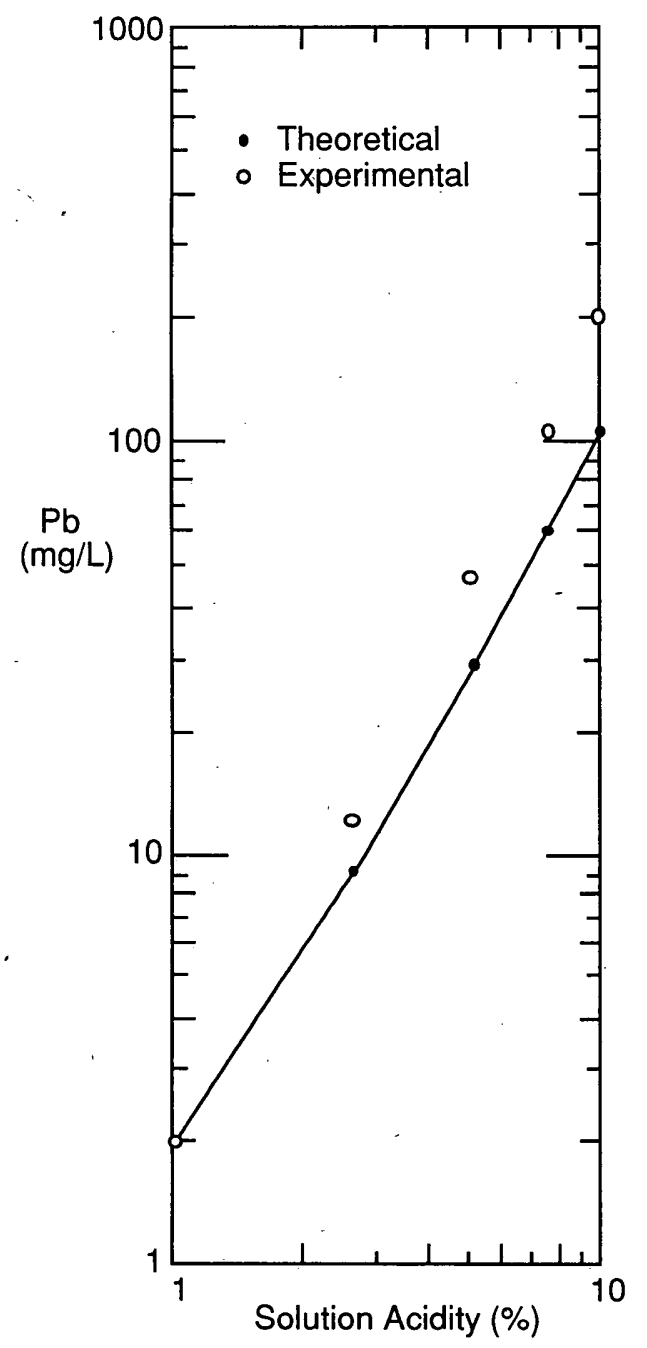

Figure 3. Theoretical and measured $\mathrm{Pb}$ concentrations versus acidity for solutions containing $\mathrm{Pb}$ and $\mathrm{H}_{2} \mathrm{CrO}_{4}$. larly and are plotted along with measured $\mathrm{Pb}$ concentrations versus solution acidity in Figure 3. Experimental $\mathrm{Pb}$ concentrations are 1.3 to 1.9 times greater than those calculated based upon $\mathrm{H}_{2} \mathrm{CrO}_{4}$ dissociation and $\mathrm{PbCrO}_{4}$ solubility. This difference is probably due to the greater solubility $\left(\mathrm{K}_{\mathrm{sp}}\right)$ of $\mathrm{PbCrO}_{4}$ in acidic than in neutral solution. This contention is supported by the difference between the experimental and the theoretical $\mathrm{Pb}$ concentrations increasing with increasing acidity for the four most acidic solutions.

Our experiments only begin to show the complex equilibria that occur with chromium (VI) in solution, and further study is warranted of the kinetic effects of acidity, analyte concentrations above $200 \mathrm{mg} / \mathrm{L}$, oxidation state of chromium in environmental samples and the precipitation of other potentially labile cations. The primary purpose of this report is to identify the problem for those researchers doing spike and recovery studies with mixed metal standards containing both $\mathrm{Cr}$ and $\mathrm{Pb}$. However, similar precipitation losses are also likely during digestion of environmental samples. Particular attention should be paid to the dissolution and analysis of leaded paints, since $\mathrm{PbCrO}_{4}$ is a common pigment. If high levels of $\mathrm{Cr}$ are present, $\mathrm{HNO}_{3}$ extracts of soils from hazardous waste sites would show low recoveries of highly toxic $\mathrm{Pb}$, resulting in undue complacency and possible inadequate remedial action.

\section{SUMMARY}

Mixed metal solutions of $\mathrm{Pb}$ and $\mathrm{Cr}$ (originally as dichromate), in the $100-\mathrm{mg} / \mathrm{L}$ concentration range, form a precipitate of $\mathrm{PbCrO}_{4}$, resulting in low recoveries of these two metals. Acidification with $10 \% \mathrm{HNO}_{3}$ will prevent precipitation at this concentration, as will a $2 \% \mathrm{HNO}_{3}$ acidification when the metal concentration is at least an order of magnitude less $(10 \mathrm{mg} / \mathrm{L})$. Sample treatment with $\mathrm{Cr}$ and $\mathrm{Pb}$ at the $100-\mathrm{mg} / \mathrm{L}$ level for recovery tests requires either the separate addition of $\mathrm{Cr}$ to the test matrix or the presence of high concentrations (about $10 \%, \mathrm{v} / \mathrm{v}$ ) of acid in the mixed metal standard.

\section{LITERATURE CITED}

Cotton, F.A. and G. Wilkinson (1988) Advanced Inorganic Chemistry, 5th ed. New York: Wiley- 
Interscience.

Hewitt, A.D. and C.M. Reynolds (1990) Dissolution of metals from soils and sediments with a microwave-nitric acid digestion technique. Atomic Spectroscopy, 11: 187-192

Katz, S.A. and S.W. Jenniss (1983) Regulatory compliance monitoring by atomic absorption spectroscopy. Deerfield Beach, Florida: Verlag Chemie International.

Lange, N.A. and G.M. Forker (1966) Lange's Handbook of Chemistry. New York: McGraw-Hill Book

- Company.
Lyde, D.C. (1961) Introduction to Qualitative Analysis. Boston: Allyn and Bacon, Inc.

Slavin, W. (1984) Graphite furnace AAS: A source book. Norwalk, Connecticut: The Perkin-Elmer Corporation, Part No. 0993-8139.

Sulcek, Z. and P. Povondra (1989) Methods of Decomposition in Inorganic Analysis. Boca Raton, Florida: CRC Press, Inc.

U.S. Army Toxic and Hazardous Material Agency (1990) Quality assurance program. USATHAMA PAM 11-41. Aberdeen Proving Ground, Maryland. 
Public reporting burden for this collection of information is estimated to average 1 hour per response, including the time for reviewing instructions, searching existing data sources, gathering and maintaining the data needed, and completing and reviewing the collection of information. Send comments regarding this burden estimate or any other aspect of this collection of information, including suggestion for reducing this burden, to Washington Headquarters Services, Directorate for Information Operations and Reports, 1215 Jefferson Davis Highway, Suite 1204, Arlington, VA 22202-4302, and to the Office of Management and Budget, Paperwork Reduction Project (0704-0188), Washington, DC 20503.

\begin{tabular}{|l|l|l|}
\hline 1. AGENCY USE ONLY (Leave blank) & 2. REPORT DATE & 3. REPORT TYPE AND DATES COVERED
\end{tabular}

4. TITLE AND SUBTITLE

October 1992

Potential Cause for Low Lead and Chromium Recoveries

During Acid Extractions

6. AUTHORS

Alan D. Hewitt and James H. Cragin

7. PERFORMING ORGANIZATION NAME(S) AND ADDRESS(ES)

8. PERFORMING ORGANIZATION

REPORT NUMBER

U.S. Army Cold Regions Research and Engineering Laboratory

Special Report 92-23

72 Lyme Road

Hanover, N.H. 03755-1290

PR: 4A161102AT24

WU: 003

9. SPONSORING/MONITORING AGENCY NAME(S) AND ADDRESS(ES)

U.S. Army Toxic and Hazardous Materials Agency

Aberdeen Proving Ground, MD 21010-5401

10. SPONSORING/MONITORING AGENCY REPORT NUMBER

Office of the Chief of Engineers

Washington, D.C. 20314

11. SUPPLEMENTARY NOTES

12a. DISTRIBUTION/AVAILABILITY STATEMENT

12b. DISTRIBUTION CODE

Approved for public release; distribution is unlimited

Available from NTIS, Springfield, Virginia 22161.

CETHA-TS-CR-92061

13. ABSTRACT (Maximum 200 words)

When high concentrations ( $\geq 100 \mathrm{mg} / \mathrm{L}$ ) of $\mathrm{Pb}$ and $\mathrm{Cr}$ (IV) are present together in solution, $\mathrm{PbCrO}_{4}$ precipitates, resulting in losses of these two metals. Moderate acidification with 1-2\% $\mathrm{HNO}_{3}$ does not prevent precipitation loss. Caution is necessary when preparing standard solutions or handling acidic extracts of environmental samples containing high levels of $\mathrm{Pb}$ and $\mathrm{Cr}$, since undetected formation of metal chromates will result in low recoveries of these metals.

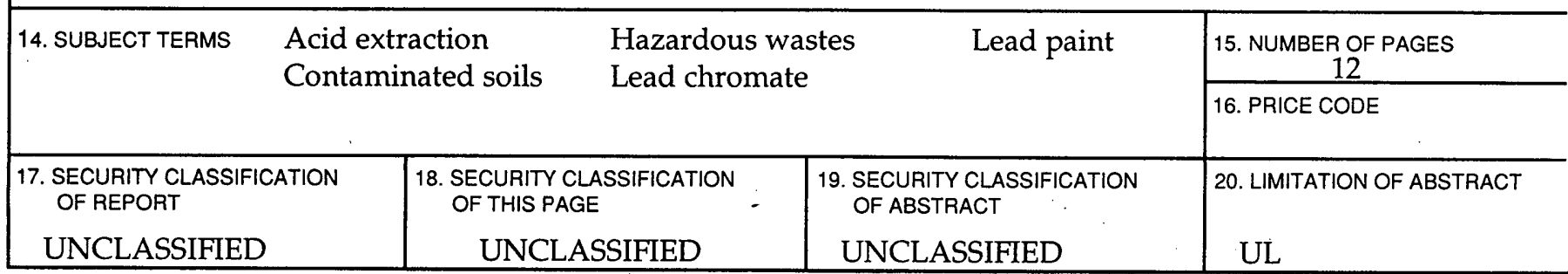

